\title{
The influence of word-knowledge on the word-frequency effect in recognition memory
}

\author{
L. R. ALLEN AND R. F. GARTON \\ UNIVERSITY OF MELBOURNE, AUSTRALIA
}

This experiment was conducted in an attempt to separate the effects of word-frequency and word-knowledge in recognition memory. Operating characteristics supported previous findings that it was easier for Ss to distinguish between old and new words having a low-frequency word count than between old and new common words. A knowledge of the meaning of a rare word was found to facilitate the discrimination of old from new low-frequency words.

The signal detection theory technique of using operating characteristics (OCs) in the study of recognition memory is derived from S's confidence ratings made to a test sequence of words containing both initial inspection and additional items (see, for example, Green \& Swets, 1966, for details). This method provides a graphic estimate, $d_{S}$, of the degree of difficulty in discriminating new from old words. As part of one such application of this technique, Schulman (1967) has demonstrated that rare words (Thorndike-Lorge frequency 1) were easier than very common words (Thorndike-Lorge frequency of A or AA) to identify as old or new; but, as Schulman has noted, the rare words used in his experiment were by no means unfamiliar ones. The experiment reported here uses OCs in an attempt to separate the effects of rarity defined in terms of the S's inability to define the meaning of a word. This is achieved by assessing the recognition performance of two groups of Ss, physics and arts students, on a sequence of test words containing both technical physics words and common words. In such a situation a physics word, e.g., "tetrode," is rare (low word count) for both physics and arts Ss, yet its meaning is likely to be rare (word knowledge) only for arts Ss.

In order to demonstrate a word-frequency effect as reported by Schulman, the OC curves of both physics and arts Ss would be expected to indicate that physics words, rather than common words, were easier to differentiate as being either old or new. In order to demonstrate a word-knowledge effect, significant differences would be expected in the OC curves of physics and arts Ss for physics words but not for common words. The superior discrimination of physics words by physics Ss would suggest that a knowledge of word meaning facilitates recognition while a superior performance by arts Ss on physics words would suggest that their rarity aided discrimination as in the wordfrequency effect.

\section{Method}

The Ss, tested in small groups, were 50 university students, 25 having completed at least one year of an honors physics course and 25 honors arts Ss having little if any science training at high school.

An inspection sequence of 60 words contained 30 common words (Thorndike-Lorge rating of 30 or more), and 30 physics words. The latter were chosen in order that they would be very familiar to second year university students enrolled for a major in physics while at the same time they would not be a part of the arts Ss ordinary vocabulary. Each word was projected onto a screen for $3 \mathrm{sec}$ using a Kodak Carousel automatic projector (Model 55OR) with a 0.5 sec interval between words. The Ss were instructed to try to remember the words appearing on the screen. There was a 3 min interval between the completion of the inspection task and the start of the recognition test. A recognition booklet contained 120 words in random order: 60 physics and 60 common words including all the inspection items ${ }^{1}$ The Ss marked these words according to whether or not they thought a word had been previously presented by marking a 5-point scale

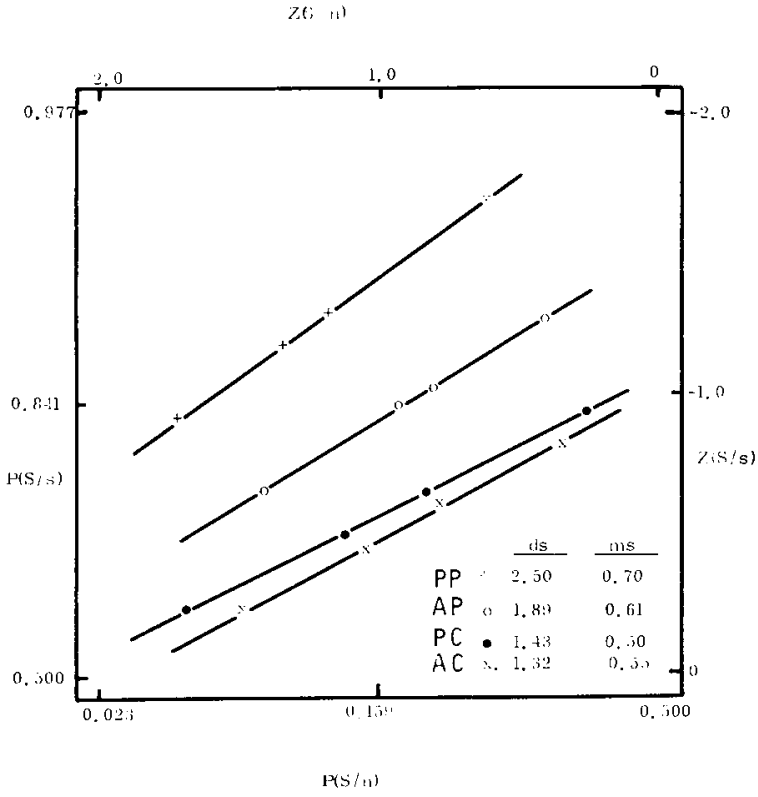

Fig. 1. Operating characteristics on a double probability plot (PP = physics Ss, physics words; $A P=$ arts Ss. physics words: $P C=$ physics $S s$, common words; $\mathrm{AC}=$ arts $\mathrm{Ss}$, common words). 
ranging from absolutely sure a word was seen before to absolutely sure a word was new.

\section{Results and Discussion}

On a double-probability plot linear OCs were drawn, for each of the four groups $(N=1500)$, through the four points obtained for the old-new discriminations. The effects of the two variables on recognition performance are evident from Fig. 1. It is apparent that physics words are easier to identify as old or new than common words, illustrated by the separation of the top two graphs from the lower two. This is true of both populations of $\mathrm{Ss}\left(\mathrm{d}_{\mathrm{s}}\right.$ 's of 2.50 and $1.89 \mathrm{vs}$ 1.32 and 1.43). This is comparable to Schulman's experimental findings. However, the separation of the top two graphs shows that physics Ss found the identification of physics words an easier task than the arts Ss $\left(d_{s} 2.50\right.$ vs 1.89). The superior recognition of physics words for physics Ss has not significantly aided the recognition of common words for this population $\left(d_{g} 1.43\right.$ vs 1.32$)$. That 18 , the two lower graphs show that the physics Ss have not found the common words much easier to recognize nor has the inferior performance of arts Ss on physics words been a result of a superior performance on common words.

These findings offer clear support for the importance of word-frequency in word recognition since the physics words were easler to recognize than very common words. What is of particular interest is that a knowledge of the meaning of low-frequency words, rather than unfamiliarity with their meaning, apparently facilitates recognition. Schulman has suggested that lowfrequency words are easier to recognize because they tend to be more distinctive semantically, since they share fewer associations than do common words. However, it seems reasonable to suppose that physics Ss would have more associations to physics words than do arts Ss. Consequently, while shared associations may inhibit recognition for common words, they apparently increase the distinctiveness of low-frequency words only in the case where their precise meaning is known.

\section{References}

GREEN, D. M., \& SWETS, J. A. Signal detection theory and psychophysics. New York: John Wiley, 1966.

SCHULMAN, A. I. Word length and rarity in recognition memory. Psychon. Sci, 1967, 9, 211-212.

THORNDIKE, E. L., \& LORGE, I. The teacher's word book of 30,000 words. New York: Columbia University Press, 1944.

\section{Note}

1. A pool of items was extracted by the authors from a dictionary of physics and administered to a pilot group of arts and physics students in order to obtain the 60 word sample used in the experiment. The 60 words chosen were easily defined by physics students while at the same time they were unfamiliar to arts students. 